\title{
Problem of Treatment of Abdominal Cryptorchidism by Orchidopexy of Fowler-Stephens from a Literature Review
}

\author{
Deh Zhou Patricia ${ }^{1, ~ *, ~ A d j o u a-N ' g o r a n ~ M a r i e ~ F l o r e ~}{ }^{1}$, Montéomo Gnaté François ${ }^{2}$, \\ Okon Abou Joël Landry ${ }^{1}$, Tré-Yavo Mireille ${ }^{1}$, Kokoua Alexandre ${ }^{1}$ \\ ${ }^{1}$ Department of Fundamental and Bioclinical Sciences, Félix Houphouët-Boigny University, Abidjan, Ivory Coast \\ ${ }^{2}$ Departement of Natural Sciences, Nangui Abrogoua University, Abidjan, Ivory Coast
}

Email address:

dehzpatricia@yahoo.fr (D. Z. Patricia)

${ }^{*}$ Corresponding author

\section{To cite this article:}

Deh Zhou Patricia, Adjoua-N'goran Marie Flore, Montéomo Gnaté François, Okon Abou Joël Landry, Tré-Yavo Mireille, Kokoua Alexandre. Problem of Treatment of Abdominal Cryptorchidism by Orchidopexy of Fowler-Stephens from a Literature Review. European Journal of Preventive Medicine. Vol. 6, No. 1, 2018, pp. 17-22. doi: 10.11648/j.ejpm.20180601.14

Received: December 14, 2017; Accepted: January 10, 2018; Published: January 29, 2018

\begin{abstract}
The purpose of this work is to show the importance of the testicular artery and the deleterious effects of its injury from a literature review. There were 75 papers relating the testicular vascularization during the period from 1949 to 2017, coming from base electronic data. The corresponding articles concerned retrospective and prospective studies, review articles published in journals with editorial board, reading and science committee. These articles were written in French and English. The results show the success rate of the Fowler-Stephens orchidopexy was varied. The testicular artery maintains testicular thermoregulation, has an endocrine and nutrition roles, besides it was the artery of fertility. The intratesticular anastomoses weren't seen between the testicular, cremasteric and differential arteries to rats, human and other mammalians. The testicular artery is the only artery that irrigates the testicular parenchyma. However, studies have observed extratesticular communications between the testicular, deferential and cremasteric arteries. In conclusion, the testicular artery is the main artery providing blood supply to the testicle. This artery plays an important role from a physiological point of view. Its lesions have important consequences on the functional and structural future of the testicle. This invites the strict respect of this artery during surgery spermatic cord or its environment.
\end{abstract}

Keywords: Abdominal Cryptorchid, Testicular Arteries, Spermatico-Deferential Anastomoses, Fowler-Stephens Orchidopexy

\section{Introduction}

Cryptorchidism is defined as stopping the migration of the testis at any point from its normal path between the lumbar region where he form and scrotum where it should be at birth through the inguinal canal $[7,9,18]$.

It's the most common birth defects of boy to the urogenital sphere $[7,9,18]$ with a rate of $3.5 \%$ [18].

Several causes may be at origin of cryptorchidism. This is fetal exposure to pesticides [1, 15] of a drinking during pregnancy $[28,44]$. The mechanical barriers to migration are linked to flight inguinal canal, spermatic vessels too short, fibrous obstruction scrotal hole [18]. Another cause may be of central origin, due to a lack of gonadotropin secretion from the pituitary and genetic factors [7].

The diagnosis takes into account the vacuity of a bursary found during the exam where palpation is performed in children. Additional tests are carried out by dosing of testosterone and abdominal exploration ultrasound, computed tomography (CT) and magnetic resonance imaging (MRI) [7].

Affected individuals often have a lower fertility to normal $[7,67]$. Some recent studies calculated relative risk of testicular cancer from 2.75 to 8 in boys with cryptorchidism $[69,73]$. Histologically, are non-palpable testicles or intraabdominal position are related to a serious loss of the cells 
germina [67].

Medical treatment with human chorionic gonadotropin (HCG) or luteinizing hormone releasing hormone (LHRH) can help testicular descent if there is no mechanical obstruction as cause cryptorchidism. However, the reported success rates vary greatly (9 to 62\%) [51]. Regarding the surgical treatment, orchidopexy is the reference treatment whose practice before 2 years even also before 1 year can reduce the risk of infertility and testicular cancer [7].

In 1959, Fowler and Stephens described an orchidopexy method which consists of the surgical lowering of the testis in the scrotum for the treatment of abdominal cryptorchidism. The Fowler-Stephens technique was initially described to treat intra-abdominal testicle when testicular artery and veins are too short to allow a good lowering in the scrotum. It involves high ligation spermatic vessels while maintaining the normal way of lowering in the inguinal canal. The distal gubernaculum attachements and collateral vessels of the anal inguinal floor remain intact. This preserves the blood approvisionment which is then provided by the development of collateral circulation through the extratesticular anastomoses between deferential and cremasteric arteries [21].

Despite its widespread use today [7, 9, 21], in 1959 Stephen and Fowler reported a significant risk of testicular atrophy (50 to 100\%). This fact would be attributable to the presence or absence and the permeability of anastomotic vessels that ensure the viability of the testicle through the vas deferens artery $[4,17,34,70]$.

So, a review of the literature is proposed to show the importance of testicular artery and the deleterious effects of the injury.

\section{Methodology of Literature Review}

Several studies on testicular vasculature during the period from 1949 to 2017 were identified and grouped into 5 classes of studies that have examined:

- the success rate of the Fowler-Stephens technique,

- the physiology role of testicular arteries,

- the effect of ligation of the testicular artery,

- the testicular collateral circulation concerning communications between testicular, deferential and cremasteric arteries;

- and the intratesticular arteries courses.

The articles were published in journals with editorial board to reading and scientific committee. The electronic databases were searched, included retrospective and prospective studies, articles of synthesis. These articles were written in French and English. Finally, 75 studies were retained.

\section{Results}

The success rate of Fowler-Stephens orchidopexy were discussed and reported success rates varied considerably. The testicular artery maintains testicular thermoregulation, has an endocrine role, nutrition and is the key input path. It has been described as the artery of fertility. Studies were indexed injury to the testicular artery to be responsible for a reduction of arterial flow to the testicle and its necrosis, of testicular atrophy and infertility. The intratesticular anastomoses weren't observed between the testicular, cremasteric and differential arteries to rats, human and other mammalians. The testicular artery is the only artery that irrigates the testicular parenchyma. However, studies have observed extratesticular communications between testicular, deferential and cremasteric arteries.

\section{Discussion}

This section was discussed to show the importance of testicular artery and the deleterious effects of its injury.

\subsection{Success Rate of Fowler - Stephens Technique}

The technique of Stephen and Fowler is one or two surgical steps and aims to empower testicular vasculature. The first time abdominal is to bind (ligature) the testicular vessels. The vascularization will then be ensured by the development of a collateral circulation from the deferential and cremasteric arteries, as well as vessels of the gubernaculum, which are always long enough to allow the lowering of the testicle. The second operative time, performed a few months after the first procedure, is then to lower the testicle in the scrotum.

The seat of the ligature is a principle for success of Fowler and Stephens technique. The two authors claim that ligation of testicular vessels should be done as far as the testis (high ligation) to ensure better collateral circulation [21]. However, this concept is questioned by Koff [33], demonstrating the contrary, the result is better if the ligation of vessels is as close to the testis (lower section).

Ransley [58] showed a significant increase in the development of collateral circulation when the procedure is performed in two stages. Moreover, Lowell [40] in turn noted improvement in the results over time, noting that collateral circulation develops best if part of the peritoneum above the testicle is dissected leaving a portion attached to the vas deferens. Becker [5], by collecting the published results until 1980 , found $73 \%$ of success. On average, the success rate is approximately $70 \%$ and testicular viability depends on the collateral circulation [64].

Kirsch [32] reports a $25 \%$ incidence of testicular atrophy. In 2010, Elvas [19] reported that Fowler and Stephens orchidopexy in 2 stages seems to have a higher success rate than the approach time (85\% against $80 \%)$. According to Bagga in 2017 [3] this success rate was $68.6 \%$.

Furthermore, studies have shown that surgical outcomes for the management of intra-abdominal testis were higher with laparoscopic orchidopexy preserving the testicular vessels compared to the Stephen-Fowler technique [20, 46].

In view of the above, we note that this technique is increasingly used although its effects are uncertain on the viability of the testis. 


\subsection{Physiological Roles of Testicular Arteries}

Several experimental studies, at the histofonctional level, testicular artery forms a dense internal arterial system which ensures the maintenance of thermoregulation of the testis with pampiniform plexus $[8,48,68]$. The arterial system has a role in nutrition and is the essential contribution pathway $[13,74]$ and causes a rhythmic variation of the arterial blood flow and helps regulate blood flow inside the testis [26]. The testicular artery has an endocrine role in the transfer of testosterone [47], the main male sex hormone which stimulates the development and testicular function [25, 37]. Furthermore, studies suggest that it is reflected artery fertility $[34,71]$.

\subsection{Effect Ligation of the Testicular Artery}

To evaluate the effect of ligation of the spermatic vessels, several experimental studies were performed on Wistar and Sprague-Dawley rats.

It has been demonstrated in testicular regression weight [61], decreased blood flow and necrosis [49].

Another study conducted showed that these rats are made infertiles by this maneuver [31].

According to Masel [41], the high Fowler-Stephens ligation [21] respects transverse spermatico-deferential anastomosis, with virtually no risk of atrophic lesions of the testis in $70 \%$. In contrast, a low ligature technique Koff [33] is the most common source of testicular atrophy and infertility; most likely by alteration of the above mentioned anastomoses that are usually located in supra-epididymal position [41].

The first two types of ligatures applied in rats resulted in a reduction in capillary blood flow in the male gonad [65] and a decrease in the population of testicular germ cells [66].

Other studies in $2004[34,70]$ have also shown that ligation of the testicular artery was responsible for over $50 \%$ of testicular lesions in rato $\mathrm{n}$ and over $90 \%$ in adults.

\subsection{Testicular Collateral Circulation}

The morphological studies that have examined the collateral circulation of the testis have instead focused their attention on the extratesticular distribution of deferential and cremasteric arteries then their extratesticular communications with the testicular artery $[2,23,35,38,45,59,62,70,75]$.

So in 1949 Harrison [22] conducted a comparative study in Wistars rats and humans using angiography. The human testicle shows that the sum of the diameters of the cremasteric and deferential arteries is equal to the diameter of the testicular artery. The diameter of the deferential artery in the rat is equal to half of that of the testicular artery. The arterial connections between the tail of the epididymis and the lower pole of the testicle on the one hand and between the head of the epididymis and the testicle on the other.

As a result, Harrison suggested that the application of the results of the division of testicular vessels in experimental animals should be done with reservation [23].

Later in 1967, [35] in the Sprague-Darley rats, the above method enabled to view extratesticular anastomoses between epididymal and testicular vessels.

Similarly, spermatico-deferential anastomosis extratesticular was observed after dissection of the same species [70].

In 1984 [38], in humans, 51 X-rayed male gonads presented a communication between the testicular, cremasteric and deferential arteries. Large caliber anastomotic channels were also counted between the testicular and deferential arteries in $87 \%$ of cases.

In 1990 [27], from 53 testicular specimens of the previous case, the spermatico-deferential anastomoses were observed near the head of the epididymis by angiography.

Sampaio in another study in 1999 [62] dissected and injected silicone gum 64 testes human fetuses aged 13 to 33 weeks. The three arteries (testicular, deferential and cremasteric) were found in $71.9 \%$ and the 2 arteries (testes and vas deferens) in $23.4 \%$ of cases.

Raman [59] meanwhile, employed micro-ruler to measure the diameter of each artery in the spermatic cord 72 men in 2004. The diameters of the arteries and deferential crémastérique range from 0.2 to $1.8 \mathrm{~mm}$, respectively 0.1 to $1.5 \mathrm{~mm}$. That of the testicular artery area ranged from 0.2 to $1.9 \mathrm{~mm}[59]$.

Artyukhin [2] in 2002 noticed that only intersystemic arterial anastomoses are found where the three vessels (testicular, cremateric and efferent duct) are braided near epididymis-efferent duct connection. He noticed that the role of these anastomoses in the maintenance of collateral circulation is negligible [2].

In 2005, [75] four undescended testes and normal were examined by vascular corrosion in human cadavers. They presented the testicular artery, deferential and cremasteric. The diameters of the 3 vessels were $1.7,1.1$ and $0.5 \mathrm{~mm}$ in the normal testicles, then $1.5,0.7$ and $0.6 \mathrm{~mm}$ in the case of undescended testes. Communication between the three arteries and that between the testicular and deferential arteries was illustrated in all the testicles.

In 2008 [45], testicular arterial supply forty human samples has been studied from dissection, vascular corrosion and radiography. Observations show that the testicular artery descends bilaterally on a regular (85\%) and tortuous (15\%) course. The cremasteric artery resulted from the inferior epigastric artery and ended near the inferior pole of the testicle. She anastomosed with the testicular artery. The deferential artery resulted from the internal iliac artery. It ended with several branches near the mediastinum testis anastomosing with branches of the testicular artery [45].

Mong the identified studies on testicular vasculature, they who have performed at the testicular parenchyma did not mention the spermatico-deferential intratesticular anastomoses in rats $[12,16,22,24,35,47,48,70,72]$, human $[12,22,24,27,42,52,53]$ and other mammals [11, $22,24,52,53,57]$. Most of these studies have used angiography methods $[12,22,27,24,35,57]$, vascular corrosion $[47,52,53]$ and conventional histology $[70,16]$.

In 2004 [34, 70], work performed systematization of 
intratesticular arteries from stepped cross-sections, extending from the upper pole to the lower pole of the rat testis. The optical microscopic observation of these preparations stained with Masson's trichrom made it possible to highlight what could be either the loop of a branch of the testicular artery or elements derived from anastomoses established between the spermatic artery and deferential artery. This has raised questions as to the existence of spermatico-deferential intratesticular anastomoses [3, 70].

In 2013, in order to address the concerns of the existence or not of spermatco-deferential intratesticular anastomoses, one study used three-dimensional reconstruction to study the intragonadic testicular artery course [71]. This was an experimental study with 100 left and right testicles from 45 immatured Wistar rats and 5 from adult control rats, aged 0 to 40 days for small rats and 3 to 7 months for adults. Testicular samples were taken under inhalation anesthesia. The serial cross-sections were performed on all testicular length then stained with Masson's trichrom for reading optical microscope. The images obtained from the selected histological sections were processed by the software version of Coreldraw 11 and Adobe Photoshop version 7 results showed the absence of spermatico-deferential intratesticular anastomoses. The testicular artery perforated the testicle by the superior pole at the hilum. This intratesticular artery was divided into two branches: a tortuous anterior branch, named anterior border artery and a regular posterior branch, named posterior edge artery. These two branches of division were terminal [71].

Most studies on the intragonadic course of the testicular artery angiography used the methods [12, 22, 24, 27, 35, 57], vascular corrosion $[47,52,53]$ and conventional histology $[16,70]$. They came to the same conclusion meaning that the testicular artery is the only artery that feeds the testicular parenchyma $[11,16,22,35,45,47,70,75]$.

\subsection{What Are the Benefits of This Review Literature}

Anatomically, the results of our research show that the testicular artery is the main artery providing blood supply of the testis $[16,23,62,27,70,75]$.

Functionally, the presence of spermatico-deferential anastomoses inside the testicle ensure the blood supply to the gonad if incision or ligature of the testicular artery [27]. However, they were not finded during our research in the testicular parenchyma. This result demonstrates the primordial role of the testicular artery in the arterial blood supply of the testis.

Clinical or practical level, the data presented here are available to complement the anatomical knowledge of the surgeon. Indeed, many studies report the injury to the testicular artery during surgical procedures interesting testis and its environment (orchidopexy and treatment of cryptorchidism, varicocele, testicular torsion, inguinal hernia) $[39,54,63]$. These lesions are responsible for a decrease in the arterial flow testicular level and its necrosis $[34,49,61$, $63,70]$, to testicular atrophy $[61]$ and infertility $[34,70]$. This despite spermatico-deferential anastomosis described by some authors [27, 45, 75$]$.
The anatomical details provided by this study can make the surgeon understand the dangers of the testicular artery in the vicinity of the cord.

Furthermore, ligation of the testicular artery in the treatment of abdominal cryptorchidism is a major cause of testicular alteration $[17,19]$.

The results of our study provided elements of discussion to the problematic of the treatment of abdominal cryptorchidism through the topographic and three-dimensional characteristics of the intragonadic branch of the testicular artery. The absence of intratesticular anastomoses between the testicular and deferential arteries and testicular artery is the only artery that irrigates the testicular parenchyma.

Despite this review contribution of the literature on the issue of the treatment of abdominal cryptorchidism by FowlerStephens orchidopexy, some limitations of the proposed approach can be stated. At first, the sources were taken from the literature, this shows that the author did not participate in the realization of the listed works. This reflects a suggestive aspect of the proposed analyzes. Then, there are also several controversies in the methodological approach of FowlerStephens orchidopexy concerning, the success rate, the clinical application of results from animal experiments and the role of anastomoses between testicular, cremasteric and deferential arteries in the maintenance of collateral circulation.

\section{Conclusion}

The results show that the testicular artery is the main artery providing blood supply to the testicle. This artery plays an important role from a physiological point of view. Its lesions have important consequences on the functional and structural future of the testicle. This calls for the strict respect of this artery during surgery of the spermatic cord or its environment.

\section{References}

[1] Andersen HR, Schmidt IM, Grandjean P and al. Impaired reproductive development in sons of women occupationally exposed to pesticides during pregnancy. Environ health perspect, 2008; 116: 566-72.

[2] Artyukhin AA. Intersystemic arterial anastomoses in testicles. Bull Exp Biol Med, 2002; 133, 6: 623-6.

[3] Bagga D, Prasad A, Grover SB, Sugandhi N, Tekchandani N and al. Evaluation of two-staged Fowler-Stephens laparoscopic orchidopexy for intra-abdominal testes. Pediatr Surg Int. 2017; doi: 10.1007/s00383-017-4170-8.

[4] Baker LA, Docimo SG, Surer I et al. A multi-institutional analysis of laparoscopic orchidopexy. BJU Int, 2001; 87: 484-9.

[5] Becker A. Urologic micro-surgery current perspectives: II orchiopexy and testicular homo-transplantation. Urol, 15: 103, 1980.

[6] Bouya PA, Odzébé WS, Avala PP, Ondongo MA, Koutaba E. Prise en charge de la cryptorchidie au centre hospitalier et universitaire de Brazzaville. Androl, 2012; 22,2: 8-11. 
[7] Braga LH, Lorenzo AJ, Romao RLP. Guide de pratique canadien de l'Association des urologues du Canada et des Urologues pédiatriques du Canada pour le diagnostic, la prise en charge et le suivi de la cryptorchidie. Can Urol Assoc J, 2017; 11 (7): E251-60.

[8] Brito LF, Silva AE, Barbosa RT, Kastelic JP. Testicular thermoregulation in Bos indicus, crossbred and Bos taurus bulls: relationship with scrotal, testicular vascular cone and testicular morphology, and effects on semen quality and sperm production. Theriogenol, 2004; 61, 3: 511-28.

[9] Casanova NC, Johnson EK, Bowen DK, Kraft KH, Wan J and al. Two-Step Fowler-Stephens orchiopexy for intra-abdominal testes: a 28-year single institution experience. J Urol, 2013; 190,4: 1371-6.

[10] Christiansen P, Müller J, Buhl S et al. Treatment of cryptorchidism with human chorionic gonadotropin or gonadotropin-releasing hormone. A double-blind controlled study of 243 boys. Horm Res, 1988; 30: 187-92.

[11] Chubb C, Desjardin C. Vasculature of the mousse, rat and rabbit testis-epididymis. Am J Anat, 1982; 165,4: 357-72.

[12] Clavert P, Maillot C, Clavert A. Angioarchitecture testiculaire: revue de la littérature et implications chirurgicales. Androl,1998; 8,4: 357-61.

[13] Collin O, Zupp JL, Setchell BP. Testicular vasomotion in different mammals. Asian J Androl, 2000; 2,4: 297-300.

[14] Daher P, Nabbout P, Feghali J, Riachy E. Is the FowlerStephens procedure still indicated for the treatment of non palpable intra abdominal testis? J Pediatr Surg, 2009; 44, 10: 1999-2003.

[15] Damgaard IN, Jensen TK, Petersen JH. Risk factors for congenital cryptorchidism in a prospective birth cohort study. Plos One, 2008; 3: 1-8.

[16] Deh ZP, Tré-Yavo M, Kokoua A, Yao GV, Sakho SS. L'artère testiculaire: étude du trajet intratesticulaire par des coupes transversales sériées chez le rat. JAMO, 2013; 7,1: 44- 49.

[17] Dénes FT, Saito FJ, Silva FA et al. Laparoscopic diagnosis and treatment of non-palpable testis. Int Braz J Urol, 2008; 34: 329-34.

[18] Elder JS. Surgical management of the undescended testis: recent advances and controversies. Eur J Pediatr Surg. 2016; 26, 5: 18-26.

[19] Elyas R, Guerra LA, Pike J, DeCarli C, Betolli M and al. Is staging beneficial for Fowler-Stephens orchiopexy? A systematic review. J Urol. 2010; 183 (5): 2012-8.

[20] Esposito C, Vallone G, Settimi A, Gonzalez Sabin MA and al. Laparoscopic orchiopexy without division of the spermatic vessels: can it be considered the procedure of choice in cases of intraabdominal testis? Surg End, 2000; 14, 7: 658- 660.

[21] Fowler RJ, Stephens FD. The role of testicular vascular anatomy in the salvage of high undescended testes. Aust. NZ. J. Surg., 29: 92-106, 1959.

[22] Harrison RG. The comparative anatomy of the blood supply of the mammalian testis. Proc Zool Soc, 1949; 119: 325-44.

[23] Harrison RG. The distribution of the vasal and cremasteric arteries to the testis and their functional importance J Anat, $1949 ; 83,3: 267-82$.
[24] Harrisson RG, Weiner JS. Vascular patterns of the mammalian testis and their functional significance. J Exp Biol, 1949; 26: 316-21.

[25] Hauschild M, Gérald T. Le développement de la fonction testiculaire. Paediatrica, 2008; 9,3: 51-55.

[26] Heinze W, Ptak W. Comparative morphological studies on the vascular systems of testes in cattle, swine, horse and dog under functional conditions. Archiv Fur Exper Veterinar Med, 1976; 30,5: 669-85.

[27] Jarow JP. Intratesticular arterial anatomy. J Androl, 1990; $11,3: 20-25$

[28] Jensen MS, Rebordosa C, Thulstrup AM, Toft G, Sørensen HT and al. Maternal use of acetaminophen, ibuprofen and acetylsalicylic acid during pregnancy and risk of cryptorchidism. Epidemiol, 2010; 21,6: 779-85.

[29] Kamisawa H, Kojima Y, Mizuno K, Imura M, Kohri K, Hayashi YS. permatogenesis after 1-stage Fowler-stephens orchiopexy in experimental cryptorchid rat model. Urol, 2010; 183, 6: 2380-84.

[30] Kastelic JP, Cook RB, Coulter GH. Contribution of the scrotum, testes, and testicular artery to scrotal/testicular thermoregulation in bulls at two ambient temperatures. Anim Reprod Sc, 1997; 45,4: 255-61.

[31] Kelly RE, Phillips JD, Fonkalsrud EW. Fertility after simulated Fowler-Stevens orchidopexy in rats. Am J Surg, 1992; 163, 2: 270- 76 .

[32] Kirsch AJ, Escala J, Duckett JW, Smith GHH, Zderic SA and al. Surgical management of the nonpalpable testis: the children's hospital of Philadelphia experience. J Urol,1998; 159: 40-43.

[33] Koff SA, Sethi PS. Treatment of high undescended testes by low spermatic vessel ligation: an alternative to the FowlerStephens technique, J. Urol, 1996; 156,2: 799- 803.

[34] Kokoua A, Tré-Yavo M, Santos KAN, Homsy Y, Mobiot ML, Gnanazan Bi N'guessan G. Valeur de l'artère testiculaire: approche histofonctionnelle et comparative chez le raton et le rat. Morphol, 2004; 88,280: 31-34.

[35] Kormano M. An angiographic study of the testicular vasculature in the postnatal rat, Z. Anat. Entw, 1967; 126, 2: 138-53.

[36] Kormano M, Suoranta H. Microvascular organization of the adult human testis. Anat Rec, 1970; 170: 31-40.

[37] Krzymowski T, Stefanczyk-Krzymowska S, Gilun P, Radomski M, Koziorowski. M A local pathway for increased testosterone supply from the testis to the epididymis, vas deferens and accessory genital glands of the rat. J Vet Sci, 2005; 8,3: 173-82.

[38] Lee LM, Johnson HW. Microdissection and radiographic studies of the arterial vasculature of the human testes. J Ped Surg, 1984; 19: 297- 301.

[39] Lemack GE, Uzzo RG, Schlegel PN, Goldstein M. Microsurgical repair of the adolescent varicocele. J Urol, 1998; 160,1: 179-81.

[40] Lowell RK. Orchiopexy for impalpable testis: high spermatic vessel division is a safe maneuver. J Urol, 1998; 160, 57-60.

[41] Masel JL, Homsy Y, Cameron D, Eller D, Kokoua A and Al. Impact of spermatic vessel ligation on rat fertility. Urol, 1998; 159, 5: 63-4. 
[42] Middlelton WD, BelI MW. Analysis of intratesticular arterial anatomy with emphasis on transmediastinal arteries. Radiol, 1993; 189: 157-60.

[43] Middleton WD, Thorne DA, Melson GL. Color Doppler ultrasound of the normal testis. Am J Roentgenol, 1989; 152: 293-97.

[44] Mongraw-Chaffin ML, Cohn BA, Cohen RD. Maternal smoking, alcohol consumption, and caffeine consumption during pregnancy in relation to a son's risk of persistent cryptorchidism: a prospective study in the child health and development studies cohort. Am J Epidemiol; 2008; 167: 257-61.

[45] Mostafa T, Labib I, El-Khayat Y, El-Rahman, El-Shahat A. Human testicular arterial supply: gross anatomy, corrosion cast and radiologic study. Fertil Steril, 2008; 90,6: 2226-30.

[46] Moursy EE, Gamal W, Hussein MM. Laparoscopic orchiopexy for non-palpable testes: Outcome of two techniques. J Pediatr Urol, 2011; 7: 178-81.

[47] Murakami T, Uno Y, Ohtsuka A, Taguchi T. The blood vascular architecture of the rat testis: a scanning electron microscopic study of corrosion casts followed by light microscopy of tissue sections. Arch Histol Cytol, 1989; 52,2: 151-72.

[48] Ohtsuka A. Microvascular architecture of the pampiniform plexus-testicular artery system in the rat a scanning electron microscope study of corrosion casts. Am J Anat, 1984; 169,3: 285-93.

[49] Ortolano V, Nasrallah PF. Spermatic vessel ligation (FowlerStephens maneuver): experimental results with regard to fertility. J Urol, 1986; 136,1: 211-13.

[50] Pascual JA, Lemmi C, Rajfer J. Variability of venous anatomy of rat testis: application to experimental testicular surgery. Microsurgery, 1992; 13,6: 335-7.

[51] Penson D, Krishnaswami S, Jules A et al. Effectiveness of hormonal and surgical therapies for cryptorchidism: A systematic review. Pediatrics 2013; 131: e1897-907.

[52] Polguj M, Jedrzejewski KS, Bolanowski W. Comparison of the blood vessel complexes of the human and bovine male gonads. Folia Morphol, 2008; 67,3: 179-85.

[53] Polguj M, Jedrzejewski KS, Dyl L, Topol M. Topographic and morphometric comparison study of the terminal part of human and bovine testicular arteries. Folia Morphol, 2009; 68,4: 271-6.

[54] Polguy M, Jedrzejewski KS, Topol M. Angioarchitecture of the bovine spermatic cord. J Morphol, 2011; 272,4: 497-502.

[55] Polguj M, Jedrzejewski KS, Topol M. Arterial supply of human and bovine testes: a topographic and morphometric comparison study. Folia Morphol, 2010; 69,4: 225-31.

[56] Polguj M, Sopiński M, Jędrzejewski K, Bolanowski W, Topol $\mathrm{M}$. Angioarchitecture of the bovine tunica albuginea vascular complex-a corrosive and histological study. Res Vet Sci, 2011; 91,2: 181-7.

[57] Rajtova V, Danko J. Vasculature of testis, epididymis and ductus deferens of Rabbit. Acta Vet Brno, 2001; 70: 3-7.

[58] Ransley PG, Vordemark JS, Caldamone AA and al. Preliminary ligation of the gonadal vessels prior to orchidopexy for the intra-abdominal testicule: a staged Fowler-Stephens procedure. Word J Urol; 2: 266, 1984.
[59] Raman JD, Goldstein M. Intraoperative characterization of arterial vasculature in spermatic cord. Urology, 2004; 64,3: 561-4.

[60] Rouiller-Fabre V, Lambrot R, Muczynski V, Coffigny H, Lécureuil C. Development and regulations of testicular functions in the human foetus. Androl, 2008; 36,9: 898-907.

[61] Salman FT, Fonkalsrud EW. Effects of spermatic vascular division for correction of high undescended testis on testicular function. Am J Surg, 1990; 160,5: 506- 10.

[62] Sampaio FJ, Favorito LA, Freitas MA, Damião R. Arterial supply of the human fetal testis during its migration. J Urol, 1999; 161, 5: 1603-05.

[63] Smith JA. Biopsy and the testicular artery of the horse. Equine vet J, 1974; 6: 81-83.

[64] Sönmez K, Can Basaklar A, Türkyilmaz Z, Demirogullari B, Numanoglu $\mathrm{V}$ and al. Neovascularization of the testicule through spermatic vessels by omental pedicle flap: a new experimental model. J Ped Surg, 1995, 30,12: 54-57.

[65] Srinivas M, Kilmartin B, Basham P, Puri P. Unilateral spermatic vessel ligation in prepubertal rats decreases microvascular blood flow to ipsilateral testis postpubertally. Pediatr Surg Int, 2003; 19,5: 395-9.

[66] Srinivas M, Kilmartin B, Das SN, Puri P. Prepubertal unilateral spermatic vessel ligation decreases haploid cell population of ipsilateral testis postpubertally in rats. Pediatr Surg Int, 2005; 21,5: 360-3.

[67] Tasian GE, Hittelman AB, Kim GE and al. Age at orchiopexy and testis palpability predict germ and Leydig cell loss: Clinical predictors of adverse histological features of cryptorchidism. J Urol, 2009; 182: 704-9.

[68] Terayama H, Naito M, Nakamura $Y$, Iimura A, Itoh $M$, Tamatsu Y. Corrosion on casts of convoluted testicular arteries in mice and rats Arch Androl, 2005; 51,6: 471-80.

[69] Trabert B, Zugna D, Richiardi L et al. Congenital malformations and testicular germ cell tumours. Int J Cancer, 2013; 133: 1900-4.

[70] Tré-Yavo M. Vascularisation interne du testicule: Approche histologique et fonctionnelle chez le rat. [Thèse Unique]. Abidjan: UFR. Sc Méd-Univ Cocody; 2004. 2: 130p.

[71] Tré-Yavo M, Deh ZP, Kokoua A, Yao GV, Ehouman A. Morphologie des artères intratesticulaires: essai de reconstruction $3 \mathrm{D}$ à partir de coupes histologiques sériées. JAMO, 2013; 7, 2: 16- 21.

[72] Weerasooriya TR, Yamamoto TT. Three-dimensional organisation of the vascular of the rat spermatic cord and testis; a scanning electron-microscopic study of vascular corrosion casts. Cel Tissue Res, 1985; 241,2: 317-23.

[73] Wood HM, Elder JS. Cryptorchidism and testicular cancer: Separating fact from fiction. J Urol, 2009; 181: 452-61.

[74] Worawut R, Takao NK, Yoshihiro H. Vascular morphology of the golden hamster spermatic cord. Arch Histol Cytol, 1989; 52,2: 183-190.

[75] Yalçin B, Komesli GH, Ozgök Y, Ozan H. Vascular anatomy of normal and undescended testes: surgical assessment of anastomotic channels between testicular and deferential arteries. Urol, 2005; 66,4: 854-7. 